\title{
Manuel Alcázar, Persona. Prólogo de Juan Fernando Sellés. Lima, edición del autor, 2018, 137 p.
}

Con gran lucidez y audacia, el autor centra la atención en el tema clave de las empresas e instituciones: la persona humana, cuyo conocimiento es tan necesario y urgente para todo directivo. En el primer capítulo, "La persona: más allá de su modo de ser", se trata del sentido de la propia persona en cuanto existente único e irrepetible, y con la "lógica de los detectives" pone de relieve la alta improbabilidad de la existencia de cada persona, de tal manera que cada quien es un caso único, por lo cual se resalta la necesidad de tener una orientación global ligada al reconocimiento del propio ser personal.

También se advierte que la persona no es la esencia tal como ha sido explorada por la ciencia. La esencia cambia a lo largo de la vida en cada ser humano. "Llamaré esencia humana al patrimonio actual que cada uno tiene en el momento actual, según el cual realmente dispone, y que es el resultado de lo que nos ha ido pasando a lo largo de la vida y de la libre disposición que hayamos ido haciendo cada quien por medio de esa naturaleza o patrimonio de partida" (p. 39). La esencia responde al qué somos, pero la persona responde al quién, no al qué. Consecuentemente, dada la importancia de la esencia, el autor propone plantearse cómo conocer la propia esencia o modo de ser.

Los siguientes capítulos, 4, 5 y 6, plantean la intimidad personal. Se subraya el no confundir el quién-uno-es y que la persona impacta en la personalidad que incluye el modo de ser (inteligencia, voluntad: incorpóreo; cuerpo-psique: corpóreo). A la vez se plantea qué no es la persona: no es el yo, que es la idea que uno tiene de sí mismo; tampoco es el concepto de 'hombre' o de 'humanidad'; no es el individuo, menos su estado de ánimo ni su identidad sexual.

La persona es un núcleo más profundo, es la propia intimidad. Así se señalan los radicales de la persona: el 'conocer personal', la libertad interior y el amar personal. Esta última, el amar libre, conlleva el aceptar, el dar y el don (y los regalos). Teniendo en cuenta que el don mayor es el del ser se resalta una advertencia de Leonardo Polo, de que el gran problema del hombre moderno es que no acepta o rechaza el ser hijo, considerando un peso insoportable tener que

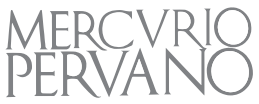


deberle la existencia a alguien. Sin embargo el gran destinatario de una persona es otra persona, especialmente la divina, ya que está en su origen, al haberle donado el ser.

Finalmente, en el último capítulo, el autor trata sobre que la intimidad es conocer radical, apertura que nace desde esa su intimidad. A este respecto sostiene un balance que sobre el conocimiento personal propone el profesor Rafael Alvira y termina con que el trabajo es manifestación del ser personal, ya que está en la dinámica del amar. 